\title{
Ovarian function in ewes made hypogonadal with GnRH antagonist and stimulated with FSH in the presence or absence of low amplitude LH pulses
}

\author{
B K Campbell, H Dobson and R J Scaramuzzi
}

CSIRO, Division of Animal Production, PO Box 239, Blacktown, New South Wales 2148, Australia

(Requests for offprints should be addressed to B K Campbell)

(B K Campbell is now at University of Edinburgh Department of Obstetrics and Gynaecology, Centre for Reproductive Biology, 37 Chalmers Street, Edinburgh EH3 9EW, UK)

(H Dobson is now at Department of Veterinary Clinical Science and Animal Husbandry, University of Liverpool, Leahurst, Neston, South Wirral L64 7TE, UK)

(R J Scaramuzzi is now at The Royal Veterinary College, University of London, Royal College Street, London NW1 OTU, UK)

\begin{abstract}
This study examined the effect of LH pulses, of similar amplitude and frequency to those found in the luteal phase, on the pattern of hormone secretion and follicle development in GnRH antagonist-suppressed ewes stimulated with exogenous FSH. This experiment was conducted on ewes with ovarian autotransplants in a continuous study. Follicle development was suppressed in 18 ewes by 3 weeks of GnRH antagonist treatment $(50 \mu \mathrm{g} / \mathrm{kg}$ per 4 days s.c.), and was then stimulated by infusion of ovine (o)FSH ( $5 \mu \mathrm{g}$ NIADDK-oFSH-16/h i.v.) for 3 days. In addition to FSH, 10 animals received pulses of LH $(2.5 \mu \mathrm{g}$ NIADDKoLH-26 i.v.) every $4 \mathrm{~h}$ for the entire period of the FSH infusion. The follicle population was determined by daily ultrasound. Samples of ovarian and jugular venous blood were collected at 4-h intervals over the period of the FSH infusion and there were three periods of intensive blood sampling (15-min intervals for $2.5 \mathrm{~h}$ at 24,48 and $72 \mathrm{~h}$ after the start of the FSH infusion) when the steroidogenic capacity of the follicles in all 18 ewes was tested around an LH challenge ( $2 \cdot 5 \mu \mathrm{g}$ i.v.).

GnRH antagonist treatment resulted in a 57\% decrease in FSH concentrations and prevented ovarian follicle
\end{abstract}

development beyond $3 \mathrm{~mm}$ in diameter. Infusion of FSH resulted in a $60 \%$ increase in FSH concentrations and stimulated the development of large antral follicles and a coincident increase in ovarian androstenedione, inhibin and oestradiol secretion in both experimental groups. In the absence of 4-hourly LH pulses basal steroid secretion was negligible $(<1 \mathrm{ng} / \mathrm{min} ; \quad P<0 \cdot 001)$. Daily $\mathrm{LH}$ challenges, however, revealed no difference in the steroidogenic capacity of the follicle population in either experimental group. Similarly, LH pulses had no effect on the growth rate and number of antral follicles stimulated by FSH infusion, or the pattern of ovarian inhibin secretion.

In conclusion, these results show that while FSH alone can stimulate the development of ovulatory sized follicles in ewes made hypogonadal with GnRH antagonist, physiological patterns of LH stimulation have no deleterious effects on FSH-stimulated follicle development and are essential for normal steroidogenesis.

Journal of Endocrinology (1998) 156, 213-222

\section{Introduction}

It is generally accepted that follicle-stimulating hormone (FSH) is the key gonadotrophin responsible for the recruitment, growth and differentiation of follicles, whereas, while luteinizing hormone (LH) has a clear role in the acute control of follicular steroidogenesis and induction of ovulation, its role in folliculogenesis is unclear (Scaramuzzi et al. 1993). The apportioning of a pivotal role to FSH in the control of folliculogenesis was initially based on a large body of data reporting associations between circulating FSH concentrations and antral follicle development (reviewed by McNeilly et al. 1991), but more recently the widespread availability of gonadotrophin-releasing hormone $(\mathrm{GnRH})$ analogues has allowed this hypothesis to be tested more directly. These studies have shown that in a number of species, including sheep (Picton et al. 1990a), cow (Gong et al. 1996a,b), monkey (Yeoman et al. 1995) and human (Howles et al. 1994), the exogenous administration of highly purified FSH, but not LH, can stimulate the development of ovulatory-sized follicles in individuals in which hypogonadotrophic hypogonadism had been induced with potent GnRH agonists. Further, these FSH-dependent follicles are capable of ovulation of fertilizable oocytes and formation of normal corpora lutea following an ovulatory stimulus (Evans et al. 1994, Howles 
et al. 1994, Gong et al. 1996b). This type of stimulatory regime has become the standard protocol for superovulation in human in vitro fertilization programmes (Howles et al. 1994).

Despite such clear evidence supporting a key role for FSH in antral follicle development, in large domestic ruminants both FSH and $\mathrm{LH}$ appear to be implicated in the growth of large oestrogenic or dominant follicles over a normal oestrous cycle. During the luteal phase, dominant follicles develop sequentially in a series of waves (sheep, Ginther et al. 1995, Souza et al. 1997a; cattle, Sirois \& Fortune 1988) and although each wave is preceded by an increase in FSH (sheep, Ginther et al. 1995, Souza et al. 1997a,b; cattle, Adams et al. 1992) the life span of a dominant follicle can be altered by modulating the pulsatile pattern of LH secretion (Savio et al. 1993). Furthermore, following luteolysis, the final maturation and development of antral follicles to ovulation is dependent on an increase in the pulsatile secretion of LH (Baird \& McNeilly 1981, McNatty et al. 1981). Studies using the $\mathrm{GnRH}$ agonist-induced hypogonadal model to examine the role of LH in folliculogenesis in sheep have produced equivocal results. While $\mathrm{LH}$ alone is unable to stimulate ovulatory follicle development in suppressed animals (Picton et al. 1990b) both LH antiserum (Picton \& McNeilly 1991) and high amplitude/low frequency LH pulses can inhibit the stimulatory action of FSH on follicular growth (Picton et al. 1990b). The ability of LH to inhibit the action of FSH in stimulating follicle development is supported by a large body of evidence that LH can suppress the superovulatory response to FSH (sheep, Wright et al. 1981, Chupin et al. 1987; cattle, Murphy et al. 1984, Chupin et al. 1987; rat, Armstrong et al. 1989), and from these data a perception has developed that LH is detrimental to follicle development.

In addition to these direct effects on ovarian follicular development, LH is the primary drive for ovarian steroid secretion, and in sheep during the normal cycle pulsatile LH stimulation of the ovary results in pulsatile secretion of both thecal-derived androgens and membrana granulosaderived oestrogens (Baird \& Scaramuzzi 1976, Campbell et al. 1990). These ovarian steroids in turn have key autocrine and paracrine actions during follicular (Hillier 1987) and oocyte (Moor et al. 1980) development in addition to their major endocrine actions in the control of pituitary gonadotrophin release (Karsch et al. 1984, Baird et al. 1991), the responsiveness of the uterus to luteolytic signals (Lamming \& Mann 1995), gamete and zygote transport (Harper 1988) and induction of behavioural oestrous (Baird \& McNeilly 1981, Fabrenys et al. 1993). Given the key role of $\mathrm{LH}$ in ovarian steroidogenesis and its potential role in follicular development, it has always been somewhat surprising that stimulatory regimes that employ FSH alone in agonist-suppressed individuals are apparently so effective.

One possible explanation for this anomaly is that $\mathrm{GnRH}$ agonists only inhibit pulsatile, not basal LH secretion
(Picton et al. 1990a,b), and that basal LH is permissive for both FSH-stimulated follicle development and ovarian steroid secretion. This hypothesis is supported by the observation that $\mathrm{LH}$ antisera can inhibit FSH-stimulated follicle development in agonist-suppressed sheep (Picton \& McNeilly 1991). In large domestic ruminants there are few data on the effect of agonist treatment on ovarian steroid secretion, but in the human it is clear that ovarian steroidogenesis is not depressed in GnRH agonistsuppressed women stimulated with highly purified urinary (Howles et al. 1994) or recombinant FSH (Devroey et al. 1994). Further, the fact that in species where overt signs of oestrus are evident, such as the pig and cow, heat is commonly observed in GnRH agonist-suppressed animals stimulated with pure FSH alone, suggests that ovarian oestradiol secretion is not depressed in these animals (pig, H M Picton, personal communication; cow, J G Gong and B K Campbell, unpublished observations). It has previously been shown that acute treatment of sheep with GnRH antagonist leads to inhibition of ovarian steroid secretion (Campbell et al. 1990) and there are reports that oestradiol secretion is minimal in GnRH antagonistsuppressed monkeys stimulated with pure FSH (Karnitis et al. 1994, Zelinski-Wooten et al. 1995). GnRH antagonist suppression may therefore represent a useful alternative model to study the modifying role of $\mathrm{LH}$ in FSH-stimulated follicle development.

The objective of the present study was to examine the effect of LH on the pattern of FSH-stimulated ovarian follicle development and ovarian steroid secretion in ewes in which hypogonadotrophic hypogonadism had been induced with a potent GnRH antagonist. This study utilized ewes with an ovarian autotransplant (Goding et al. 1967 ) as this model allows the morphological and endocrine responses of the ovary to be assessed simultaneously and repeatedly in conscious animals.

\section{Materials and Methods}

\section{Experimental animals}

Border Leicester Merino crossbred ewes $(n=18$; mean weight $65 \pm 1 \mathrm{~kg}$ ), with an autotransplanted ovary (Goding et al. 1967) were studied in the mid-breeding season (May). During the 3-week pretreatment with GnRH antagonist, the animals were kept outdoors and grazed normally with a ram fitted with a marking harness to verify the lack of oestrus behaviour (Radford et al. 1960). Prior to the experimental period, the animals were placed in metabolism crates in temperature-controlled rooms $\left(20^{\circ} \mathrm{C}\right)$ under natural lighting at the CSIRO Division of Animal Production, Blacktown, NSW, Australia. The animals were fed a maintenance diet of $600 \mathrm{~g}$ daily of a pelleted ration of $60 \%$ lucerne and $40 \%$ oats and had been habituated to the housing conditions prior to the start of the experiment. 
On the day prior to the start of blood sampling all animals, under local anaesthesia (Xylocaine, Astra Pharmaceuticals Pty Ltd, North Ryde, NSW, Australia), had a silastic cannula inserted into both jugular veins, as previously described (Campbell et al. 1994), in order to facilitate the collection of ovarian and jugular venous blood. In addition a third silastic cannula $(0.8 \mathrm{~mm}$ inside diameter $\times 1.7 \mathrm{~mm}$ outside diameter; 602-175, Dow Corning, Midland, MI, USA) was inserted into the left jugular vein, caudal to the first cannula, for infusion of FSH. After cannulation, the animals were treated prophylactically with antibiotics (4 $\mathrm{ml}$ i.m., Hydropen, Bomac Laboratories, Castle Hill, NSW, Australia) and heparin (5000 IU i.v./12 h, Fisons Pharmaceuticals, Castle Hill, NSW, Australia).

\section{Hormone solutions}

The GnRH antagonist ([AcDNal ${ }^{1}, \mathrm{DCpa}^{2}, \mathrm{DTrp}^{3}, \mathrm{DArg}^{6}$, $\mathrm{DAla}^{10} \mathrm{]}-\mathrm{GnRH}$; donated by the Salk Institute and Centre for Population Research, National Institute of Child Health and Human Development) was dissolved in 0.9\% $(\mathrm{w} / \mathrm{v})$ sterile saline to a concentration of $1 \mathrm{mg} / \mathrm{ml}$ and administered s.c. (Campbell et al. 1990, 1992). The FSH used was NIADDK-ovine (o)FSH-S16 (bioactivity 20 times NIH-oFSH-S1 and LH contamination 0.04 times $\mathrm{NIH}-\mathrm{LH}-\mathrm{S} 1 / \mathrm{mg}$ ) whereas the LH was NIADDK-oLHS26 (bioactivity $2 \cdot 3$ times NIH-oLH-S1 and FSH contamination $<0.5 \%$ by weight). Both gonadotrophins were dissolved in $0.9 \%(\mathrm{w} / \mathrm{v})$ sterile saline with $1 \%(\mathrm{v} / \mathrm{v})$ normal sheep plasma. FSH was continuously infused with the aid of Harvard infusion pumps whereas LH was administered i.v. as a $2 \mathrm{ml}$ bolus injection.

\section{Experimental design}

Ovarian suppression period In order to suppress ovarian function, all ewes were pretreated with GnRH antagonist $(50 \mu \mathrm{g} / \mathrm{kg}$ s.c.) at intervals of $4-6$ days for 3 weeks prior to the start of the experiment. Ewes were also treated over this period with intravaginal progestagen pessaries (medroxyprogesterone acetate, Repromap, Upjohn Pty Ltd, Rydalmere, NSW, Australia), which were changed at 10- to 12-day intervals, in order to more closely mimic the steroidal environment of a normal luteal phase. All ewes received cloprostenol (125 $\mu \mathrm{g}$ i.m., Estrumate, ICI plc, Macclesfield, Cheshire, UK) at the start of the pretreatment period to ensure the absence of corpora lutea. Samples of jugular venous blood were collected by venipuncture at each time of $\mathrm{GnRH}$ antagonist injection, for the determination of $\mathrm{FSH}, \mathrm{LH}$ and progesterone concentrations.

Experimental period The animals were randomly divided into two groups. Group $1(n=8)$ were treated with
FSH $(5 \mu \mathrm{g} / \mathrm{h})$ for 3 days without $\mathrm{LH}$ and Group $2(n=10)$ were treated with FSH $(5 \mu \mathrm{g} / \mathrm{h})$ for 3 days with $\mathrm{LH}$ $(2.5 \mu \mathrm{g}$ administered as a bolus injection every $4 \mathrm{~h})$. This dose of LH has been shown to induce an LH pulse of similar magnitude to that observed during a normal luteal phase (Baird et al. 1976, Wallace \& McNeilly 1986, Whisnant et al. 1991). Ovarian (5 ml) and jugular (3 ml) venous blood samples were taken every $4 \mathrm{~h}$ over the experimental period and there were three periods of intensive blood sampling 24, 48 and $72 \mathrm{~h}$ after the start of FSH infusion. During intensive periods, both peripheral $(2 \mathrm{ml})$ and ovarian venous $(3 \mathrm{ml})$ blood samples were collected at 15-min intervals for $15 \mathrm{~min}$ before and $2 \mathrm{~h}$ after an $\mathrm{LH}$ challenge $(2 \cdot 5 \mu \mathrm{g}$ i.v.) which was administered to both Groups 1 and 2 . The blood was centrifuged at $4{ }^{\circ} \mathrm{C}$ and the plasma stored at $-20{ }^{\circ} \mathrm{C}$ until analysis. To allow calculation of ovarian hormone secretion rates all collections of ovarian venous blood every $4 \mathrm{~h}$, and every hour during the intensive sampling periods, were timed. The samples of ovarian venous blood taken every $4 \mathrm{~h}$ were collected 20-30 min after LH was administered to Group 2 ewes, as this is the time taken for maximal steroidogenic responses to LH stimulation (Campbell et al. 1990). After correcting for the haematocrit (Collett et al. 1973) and jugular contribution (inhibin only), the rates of ovarian secretion of oestradiol, androstenedione, progesterone and inhibin were calculated.

\section{Ovarian scanning procedure}

The ovarian follicle population was examined daily as previously described (Campbell et al. 1994). Briefly, the diameter of the antral cavity and position of all follicles greater than $2 \mathrm{~mm}$ in diameter in the medial/lateral, dorsal/ventral and cranial/caudal planes were determined using a combined sector real time ultrasound scanner with a sector $7.5 \mathrm{MHz}$ transducer probe (Ausonics, Lane Cove, NSW, Australia).

\section{Hormone assays}

Plasma concentrations of LH, FSH, androstenedione (Campbell et al. 1990), immunoactive inhibin (McNeilly et al. 1989), oestradiol and progesterone (Campbell et al. 1994) were determined using previously described radioimmunoassays. The sensitivities of the assays for LH, FSH, androstenedione, inhibin, oestradiol and progesterone were $0 \cdot 2 \mathrm{ng} \mathrm{NIH}-\mathrm{LH}-\mathrm{S} 20 / \mathrm{ml}, 0 \cdot 1 \mathrm{ng}$ NIAMDD-FSH$\mathrm{RP} 1 / \mathrm{ml}, 20 \mathrm{pg}$ androstenedione/ml, $35 \mathrm{pg} 1-26 \alpha$-subunit porcine inhibin $/ \mathrm{ml}, 15 \mathrm{pg}$ oestradiol $/ \mathrm{ml}$ and $200 \mathrm{pg}$ progesterone $/ \mathrm{ml}$. The intra- and interassay coefficients of variation for $\mathrm{LH}, \mathrm{FSH}$, androstenedione, inhibin, oestradiol and progesterone were $4 \cdot 3$ and $5 \cdot 4 \%, 1 \cdot 7$ and $2 \cdot 8 \%, 6 \cdot 2$ and $9 \cdot 1 \%, 5 \cdot 2$ and $10 \cdot 5 \%, 6 \cdot 4$ and $10 \cdot 2 \%$, and $7 \cdot 9$ and $10 \cdot 0 \%$ respectively. 


\section{Statistical analysis}

Statistical analysis of hormonal profile data was performed by repeated measures analysis of variance (ANOVA) with log-transformed data partitioned on the basis of treatment and time. The characteristics of pulsatile $\mathrm{LH}$ secretion were determined using the Munro pulse analysis program (Zaristow Software, West Morham, Haddington, East Lothian, UK). The steroidogenic pulsatile response to an LH pulse was determined by grouping the data from individual profiles around the time of each $\mathrm{LH}$ injection and calculating basal secretion and pulse amplitude (defined as pulse height minus pulse nadir). In addition, the overall mean of LH, oestradiol and androstenedione secretion during the periods of intensive sampling were calculated. Comparisons between treatment groups on these determinants of pulsatile hormone secretion were made by repeated samples ANOVA. The effect of treatment on follicle numbers was determined by repeated sample ANOVA following $\sqrt{ }(x+0 \cdot 5)$ transformation.

\section{Results}

\section{Peripheral hormone concentrations}

The 3-week GnRH antagonist pretreatment resulted in a marked decrease $(P<0 \cdot 01)$ in both jugular venous plasma FSH concentrations $(0 \cdot 85 \pm 0.07 \mathrm{ng} \mathrm{FSH} / \mathrm{ml}$ before treatment to $0.48 \pm 0.02 \mathrm{ng} \mathrm{FSH} / \mathrm{ml}$ after pretreatment; mean \pm S.E.M., $n=18)$ and LH concentrations $(0.55 \pm$ $0.09 \mathrm{ng} \mathrm{LH} / \mathrm{ml}$ before treatment to less than $0.2 \mathrm{ng}$ $\mathrm{LH} / \mathrm{ml}$ after pretreatment; mean \pm s.E.M., $n=18)$. Infusion of FSH restored FSH concentrations to pre-GnRH antagonist treatment values $(P<0 \cdot 001)$ within $8 \mathrm{~h}$ of the start of the infusion in both experimental groups (Fig. 1). Mean FSH concentrations remained at approximately $0.8 \mathrm{ng} / \mathrm{ml}$ for the remainder of the experimental period but did decline slightly in some animals (Fig. 2). Injection of LH pulses every $4 \mathrm{~h}$ had no effect on jugular FSH concentrations but, as expected, did result in a marked increase $(P<0.001)$ in mean $\mathrm{LH}$ concentrations. Interestingly, within $24 \mathrm{~h}$ of the start of treatment, basal LH declined $(P<0.01)$ and then remained stable for the rest of the experimental period at values similar to those detected before $\mathrm{GnRH}$ antagonist treatment. In contrast, mean $\mathrm{LH}$ concentrations in non-LH treated animals remained at the detection limit of the assay for the entire experimental period (Fig. 1). Analysis of the LH pulse profiles derived from the period of intensive blood sampling showed that injection of $2.5 \mu \mathrm{g} \mathrm{LH}$ resulted in a pulse with an amplitude of $3.8 \pm 0.3 \mathrm{ng} \mathrm{LH} / \mathrm{ml}$ (mean \pm s.E.M., $n=18$ ) superimposed on a baseline concentration of $0.19 \pm$ $0.04 \mathrm{ng} \mathrm{LH} / \mathrm{ml}$ (mean \pm s.E.M., $n=18$ ). There were no significant treatment effects on pulse amplitude or pulse nadir (data not shown) but LH pulse amplitude and mean secretion declined with time $(P<0 \cdot 05)$ after the start of FSH infusion (Table 1).

\section{Ovarian hormone secretion rates}

Basal ovarian oestradiol and androstenedione secretion in ewes not frequently treated with LH remained below $1 \mathrm{ng} / \mathrm{min}$ for the entire experimental period (Fig. 1). In contrast, in Group 2 ewes (LH treated), basal androstenedione secretion increased $(P<0 \cdot 001)$ within $8 \mathrm{~h}$ of the start of FSH infusion and continued to increase $(P<0 \cdot 01)$ during the remainder of the experimental period. Basal oestradiol secretion was also stimulated $(P<0 \cdot 01)$ by LH treatment and although the rate of the increase from the start of FSH infusion was slower than that for androstenedione, taking approximately $24 \mathrm{~h}$ to increase markedly $(P<0 \cdot 01)$, values continued to increase $(P<0 \cdot 001)$ for the remainder of the experimental period. Ovarian immunoreactive inhibin secretion remained relatively stable for the first $24 \mathrm{~h}$ of the FSH infusion, then increased $(P<0 \cdot 001)$ in both groups, reaching a plateau around $64 \mathrm{~h}$ after the start of FSH infusion (Fig. 1). There were no differences in the level or pattern of inhibin secretion between Groups 1 and 2 .

In contrast to basal steroid secretion, when the steroidogenic capacity of the follicle population in both groups was tested by LH challenges, there were no significant differences between the groups in the oestradiol or androstenedione pulse profiles obtained 24,48 and $72 \mathrm{~h}$ after the start of FSH infusion (Fig. 1). Throughout the FSH infusion, however, there was a sequential increase in ovarian pulse nadir $(P<0 \cdot 05)$, pulse amplitude $(P<0 \cdot 001)$ and mean secretion $(P<0 \cdot 001)$ with time $(24,48$ and $72 \mathrm{~h}$ ) for both oestradiol and androstenedione (Fig. 1; Table 1).

\section{Follicle development}

Following 3 weeks of $\mathrm{GnRH}$ antagonist pretreatment there were no ovarian follicles greater than $3 \mathrm{~mm}$ in diameter and few follicles greater than $2 \mathrm{~mm}$ in diameter (Figs. 2 and 3). Infusion of FSH stimulated follicle growth and this was reflected in a sequential increase $(P<0.001)$ in both follicle diameter (Figs 2 and $3 a$ ) and total number of follicles (Figs 2 and $3 b$ ). The increase in total follicle number was mainly composed of a sequential increase in the number of large $(\geq 3.5 \mathrm{~mm}$ in diameter; $P<0.001)$ follicles, whereas the number of small follicles increased $(P<0 \cdot 05)$ after 1 day of FSH infusion and then remained stable for the rest of the infusion period. Co-administration of pulses of LH every $4 \mathrm{~h}$ had no effect on the ability of FSH to stimulate follicle diameter (Fig. 3a) or follicle number (data not shown).

Follicle development and ovarian hormone secretion were temporally related and this is illustrated by Fig. 2 which shows follicle and hormonal data from an individual 

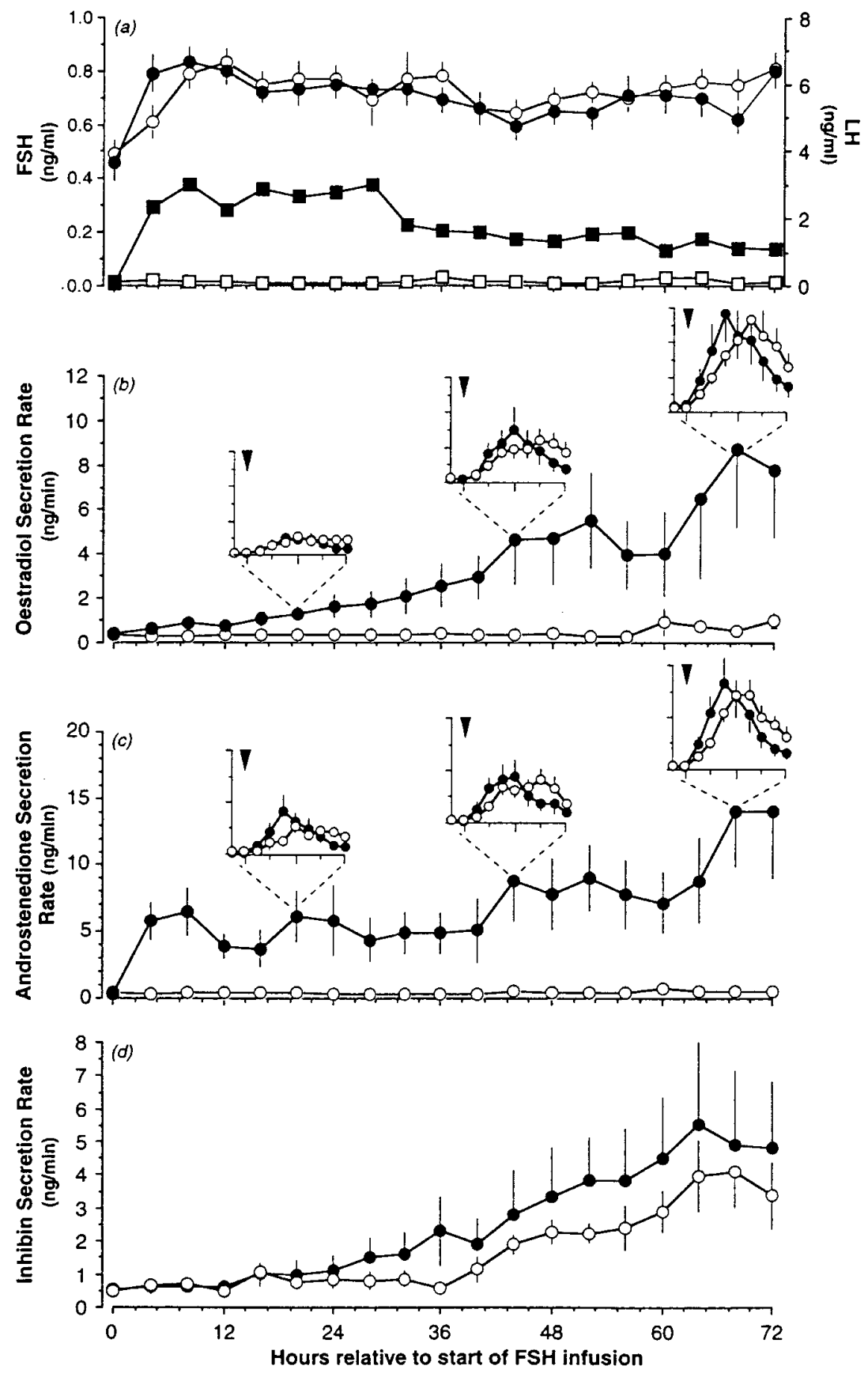

Figure 1 The effect of a 3-day infusion of oFSH-16 (5 $\mu \mathrm{g} / \mathrm{h}$ i.v.) into ewes with ovarian autotransplants (pretreated for 3 weeks with GnRH antagonist to suppress endogenous gonadotrophins and hence large antral follicle development) that received no $\mathrm{LH}(n=8 ; \bigcirc$, $\square)$ or LH $(2.5 \mu \mathrm{g}$ oLH-S2 i.v.) every $4 \mathrm{~h}(n=10 ; 0, \mathbf{0})$. Effects on (a) peripheral FSH $(\bigcirc, \boldsymbol{\bullet}$ and $\mathrm{LH}(\square, \mathbf{\square})$ concentrations; $(b)$ ovarian oestradiol secretion $(\bigcirc, \mathbf{Q})$; $(c)$ ovarian androstenedione secretion $(O, \mathbf{0})$; and $(d)$ ovarian inhibin secretion $(O, \mathbf{0})$ determined from samples of blood taken every $4 \mathrm{~h}$. The inserts show the secretory response to a single test pulse of $\mathrm{LH}(2 \cdot 5 \mu \mathrm{g}$ oLH-26 i.v., arrows) given to both groups of ewes 24,48 and $72 \mathrm{~h}$ after the start of FSH infusion (the scale on the $\mathrm{Y}$-axis is the same as the main figure). Values are means \pm S.E.M. (S.E.M. for LH values are within the symbol). 


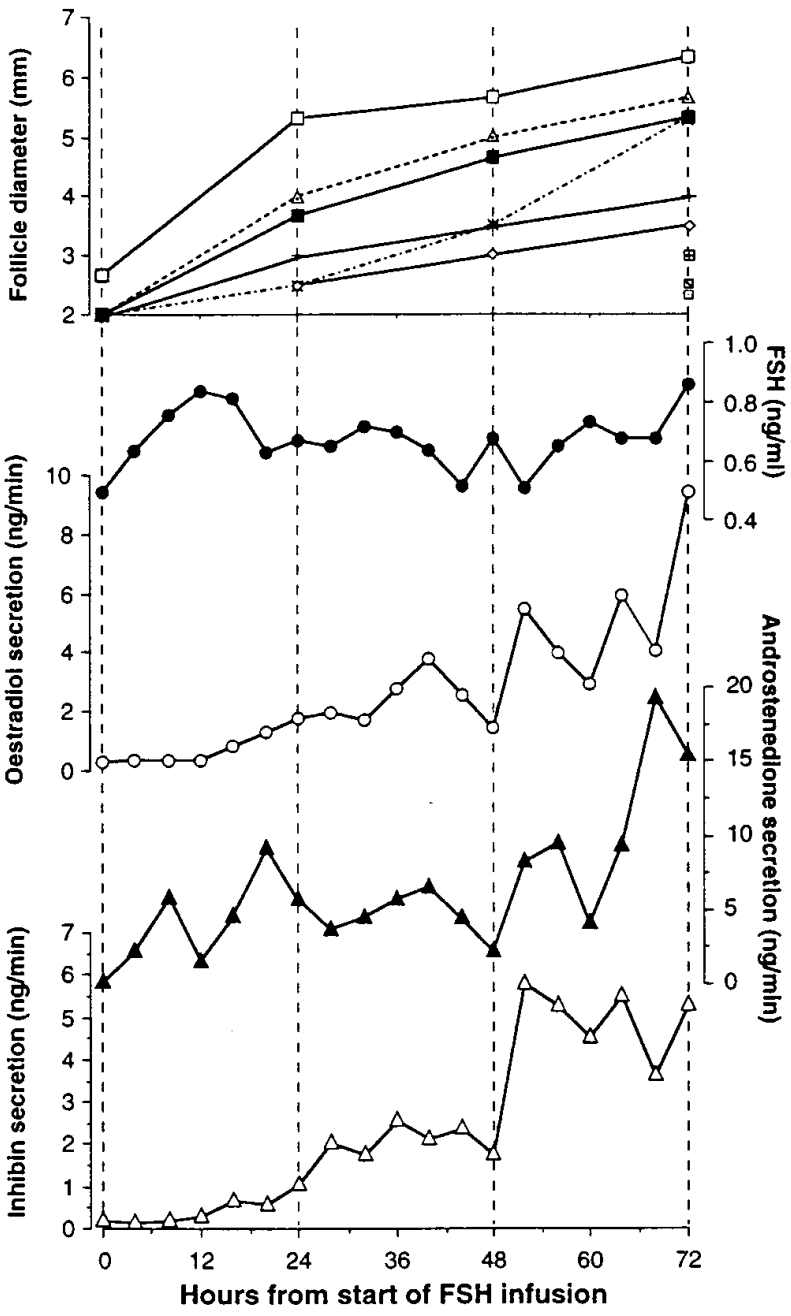

Figure 2 The effect of a 3-day infusion of FSH (oFSH-16; $5 \mu \mathrm{g} / \mathrm{h}$ i.v.) in the presence of 4 -hourly pulses of $\mathrm{LH}(2.5 \mu \mathrm{g}$ oLH-26 i.v. $)$ on the pattern of ovarian follicle development (top panel; each symbol represents the diameter of individual follicles identified by daily ultrasound) and jugular venous FSH concentrations $(\bullet)$, ovarian oestradiol $(\bigcirc)$, androstenedione $(\boldsymbol{\Delta})$ and inhibin $(\triangle)$ secretion in an individual animal pretreated with GnRH antagonist to suppress endogenous gonadotrophins and hence large antral follicle development.

ewe from Group 2. The first day of FSH infusion stimulated the rapid recruitment of a number of small follicles and this was reflected primarily by an increase in ovarian androstenedione secretion. Follicle development continued during the second day of FSH treatment, but during this period androstenedione secretion remained stable and both ovarian inhibin and oestradiol secretion increased markedly while FSH concentrations tended to decline. The third day of FSH infusion saw a decline in the rate of large follicle development, the recruitment of a second cohort of small follicles and a marked increase in the ovarian secretion of oestradiol, androstenedione and inhibin.

\section{Discussion}

The findings described in this paper provide, for the first time, a longitudinal description of the pattern of follicle development and ovarian steroid secretion in $\mathrm{GnRH}$ antagonist-suppressed ewes in which follicle development has been stimulated by the infusion of physiological doses of FSH. The results show that while FSH alone can stimulate the development of preovulatory-sized follicles in hypogonadal sheep, these follicles, in the absence of pulsatile LH, secrete negligible quantities of androstenedione and oestradiol, thus confirming that $\mathrm{GnRH}$ antagonist treatment inhibits both immunoactive and bioactive $\mathrm{LH}$ secretion. Furthermore, these data show that LH pulses, of similar amplitude and frequency to those observed during a normal luteal phase, restore ovarian steroid secretion without any effect on the pattern of FSH-stimulated follicle development.

The absence of ovarian steroid secretion in hypogonadal ewes stimulated with FSH alone not only emphasizes the key role that LH has in the control of ovarian steroidogenesis but also confirms that $\mathrm{GnRH}$ antagonist treatment inhibited both immunoactive and bioactive LH secretion. GnRH antagonist treatment, while being as equally effective as GnRH agonist in suppressing FSH (50-60\%; Picton et al. 1990a) appears to result in lower basal immunoactive LH concentrations (values approximately $0 \cdot 2 \mathrm{ng} / \mathrm{ml}$ ) than GnRH agonist (values approximately $1 \mathrm{ng} / \mathrm{ml}$; Picton et al. 1990b). It is clear, from the responses observed to daily $\mathrm{LH}$ challenges, that the follicle population retains the ability to elicit acute steroidogenic responses to $\mathrm{LH}$, despite the absence of the normal patterns of episodic stimulation. This result shows very clearly that the level of ovarian steroid secretion depends not only on the presence of steroidogenic follicles in the ovary but also on the degree of $\mathrm{LH}$ drive. This is an important concept, because during reproductive phases when LH pulse frequency is low, such as during anoestrus (Souza et al. 1996) or during the midto late-luteal phase (Souza et al. 1997a), ovarian oestradiol secretion is low, despite the presence of large oestrogenic ovarian follicles. The lack of ovarian steroid secretion in $\mathrm{GnRH}$ antagonist-suppressed ewes stimulated with FSH emphasizes the unphysiological nature of the steroidal environment induced by such regimes and strongly suggests that physiological regimes of $\mathrm{LH}$ replacement would be needed if stimulatory regimes that employed $\mathrm{GnRH}$ antagonist in combination with recombinant FSH were used in a clinical context.

The second major finding of this work was that the addition of physiological-sized pulses of LH (Wallace \& McNeilly 1986) had no effect, deleterious or otherwise, on the pattern of FSH-stimulated follicle development. This finding conflicts with a number of studies that have reported a deleterious effect of LH on FSH-stimulated follicle development (Chupin et al. 1987, Picton et al. 1990b). But it is consistent with the observation that 
Table 1 Values of pulsatile LH and ovarian steroid secretion (mean \pm S.E.M.) determined after a single bolus injection of $\mathrm{LH}(2.5 \mu \mathrm{g} \mathrm{LH}-\mathrm{S} 26$ i.v.), given $24,48,72 \mathrm{~h}$ after the start of FSH infusion $(5 \mu \mathrm{g} / \mathrm{h}$ i.v. $)$, to ewes $(n=18)$ with ovarian autotransplants pretreated with GnRH antagonist for 3 weeks to suppress ovarian follicle development. As there were no differences between Groups 1 and 2 for these values (see Fig. 1), data have been pooled across groups for this table

\begin{tabular}{|c|c|c|c|c|}
\hline & Time $(h)$ & Pulse amplitude & Basal secretion & Mean secretion \\
\hline \multicolumn{5}{|l|}{ Hormone } \\
\hline \multirow[t]{4}{*}{$\mathrm{LH}(\mathrm{ng} / \mathrm{ml})$} & 24 & $4 \cdot 9 \pm 0 \cdot 5$ & $0 \cdot 2 \pm 0 \cdot 1$ & $1 \cdot 1 \pm 0 \cdot 1$ \\
\hline & 48 & $2 \cdot 9 \pm 0 \cdot 3^{*}$ & $0 \cdot 2 \pm 0 \cdot 1$ & $0 \cdot 6 \pm 0 \cdot 1^{*}$ \\
\hline & 72 & $3 \cdot 6 \pm 0 \cdot 5$ & $0 \cdot 2 \pm 0 \cdot 1$ & $0 \cdot 7 \pm 0 \cdot 1$ \\
\hline & & $P<0.05$ & $P>0.05$ & $P<0.01$ \\
\hline \multirow[t]{4}{*}{ Oestradiol (ng/min) } & 24 & $1 \cdot 7 \pm 0 \cdot 3$ & $0 \cdot 3 \pm 0 \cdot 1$ & $1 \cdot 4 \pm 0 \cdot 2$ \\
\hline & 48 & $4 \cdot 6 \pm 0 \cdot 8^{* *}$ & $0 \cdot 4 \pm 0 \cdot 1$ & $3 \cdot 0 \pm 0 \cdot 5^{* *}$ \\
\hline & 72 & $7 \cdot 8 \pm 1 \cdot 5^{*}$ & $0 \cdot 8 \pm 0 \cdot 2^{*}$ & $5 \cdot 0 \pm 1 \cdot 0^{*}$ \\
\hline & & $P<0 \cdot 001$ & $P<0.05$ & $P<0 \cdot 01$ \\
\hline \multirow[t]{4}{*}{ Androstenedione (ng/min) } & 24 & $5 \cdot 0 \pm 1 \cdot 3$ & $0 \cdot 3 \pm 0 \cdot 1$ & $3 \cdot 1 \pm 0 \cdot 7$ \\
\hline & 48 & $7 \cdot 5 \pm 1 \cdot 4^{*}$ & $0 \cdot 5 \pm 0 \cdot 1$ & $4 \cdot 8 \pm 0 \cdot 8^{* *}$ \\
\hline & 72 & $13 \cdot 4 \pm 2 \cdot 5^{* *}$ & $0 \cdot 6 \pm 0 \cdot 1$ & $7 \cdot 2 \pm 1 \cdot 3^{*}$ \\
\hline & & $P<0.001$ & $P<0.05$ & $P<0.001$ \\
\hline
\end{tabular}

$P$ indicates overall significance of time effect. ${ }^{*} P<0 \cdot 05,{ }^{* *} P<0 \cdot 01$ from preceding time point (repeated samples ANOVA).

FSH-dependent follicle development in sheep (Webb \& Gauld 1987, Souza et al. 1997a,b), and in a number of mono-ovulatory species (human, Baird 1983; cow, Webb et al. 1992), occurs during normal ovulatory cycles when LH secretion is pulsatile. The most likely explanation for the difference between the deleterious effects of $\mathrm{LH}$ pulses on FSH-stimulated follicle development reported previously and the lack of effect observed in the present experiment is the difference in LH pulse amplitude induced by injection of LH. Thus, it is likely that large amplitude pulses have a deleterious effect on the follicle population in a manner analogous to the fall in steroid secretion and induction of atresia in the antral follicle population that occurs following the preovulatory $\mathrm{LH}$ surge (Baird \& McNeilly 1981). The recent finding that sheep follicular cells are exquisitely sensitive to $\mathrm{LH}$ in culture, and that continuous doses as low as $1 \mathrm{ng} / \mathrm{ml}$ can inhibit steroidogenesis (Campbell et al. 1996), supports this explanation.

In contrast to the results of the present study, and as detailed in the Introduction, in large domestic ruminants both FSH and LH appear to be implicated in the growth of large oestrogenic or dominant follicles over a normal oestrous cycle. However, data from our laboratory showing that FSH-dependent follicles can transfer their gonadotrophic dependence from FSH to $\mathrm{LH}$, if it is delivered as a series of high frequency low amplitude pulses (Campbell et al. 1993), suggest that the involvement of $\mathrm{LH}$ in dominant follicle development is restricted to the terminal stages of follicular differentiation and may represent one of the mechanisms of follicle selection. The fact that follicles grow normally in the absence of $\mathrm{LH}$, when follicular steroidogenesis is limited, is somewhat surprising given the widely held belief that steroids are important intrafollicular modulators of follicle development (Hillier 1987). However, while it is possible that basal levels of LH are sufficient to maintain intrafollicular steroid concentrations, there have been no reports of steroid concentrations in the follicular fluid of FSH-stimulated GnRH antagonisttreated ewes.

The use of the ovarian autotransplant model in this experiment allowed a longitudinal description of the development of individual follicles and comparison of the pattern of follicle development with the precise pattern of hormone secretion in suppressed animals stimulated with FSH. The sequence of events observed following FSH stimulation was an initial increase in the number of small follicles, reflected hormonally by an initial increase in ovarian androstenedione secretion, followed by an increase in ovarian inhibin and oestradiol secretion as the recruited follicles continued to grow and mature under the influence of FSH. These follicular and ovarian secretory responses to FSH infusion are similar to those observed during FSHstimulated follicle development in ewes immunized against inhibin (Campbell \& Scaramuzzi 1995, Campbell et al. 1995) or following the FSH rebound in ewes treated with follicular fluid (Baird et al. 1990, Campbell et al. 1991).

In conclusion, these results show that while FSH alone can stimulate the development of ovulatory sized follicles in ewes made hypogonadal with GnRH antagonist, physiological patterns of LH stimulation have no deleterious effects on FSH-stimulated follicle development and are essential for normal steroidogenesis. Thus, in clinical or production contexts, LH replacement in GnRH antagonist-suppressed individuals is essential if a normal steroidal environment is to be maintained and $\mathrm{LH}$ will not antagonize the follicular response to FSH stimulation if physiological replacement regimes are used. 

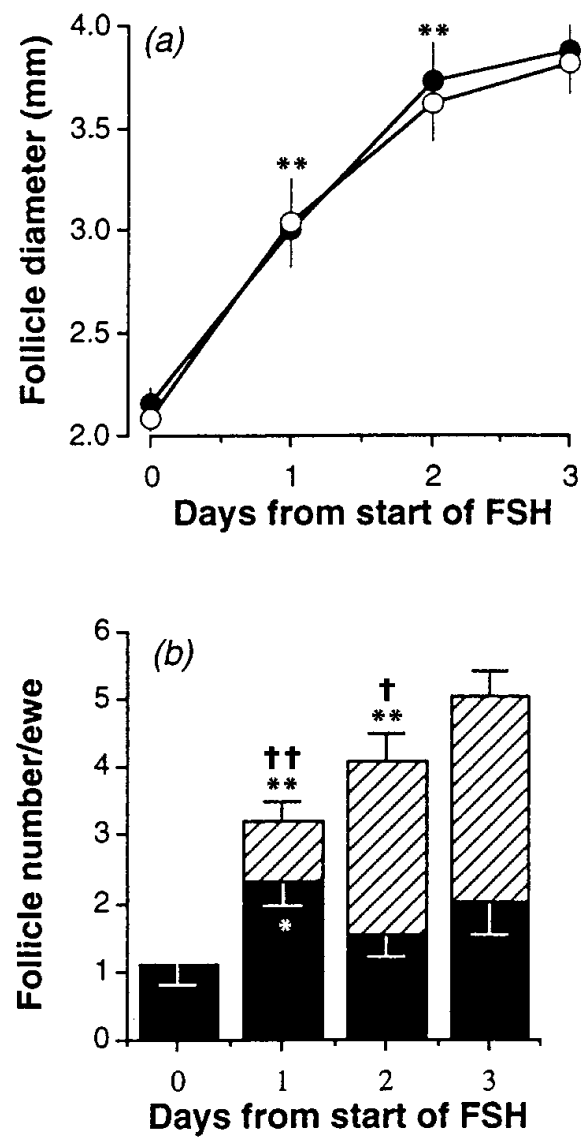

Figure 3 The effect of a 3-day infusion of FSH (oFSH-16; $5 \mu \mathrm{g} / \mathrm{h}$ i.v.) on (a) the mean diameter of all follicles detected by daily ultrasound in the ovaries of GnRH antagonist-suppressed ewes which received either no $\mathrm{LH}$ pulses $(n=8)$ or 4-hourly pulses of $\mathrm{LH}$ $(2.5 \mu \mathrm{g}$ oLH-26 i.v., $n=10)$; and $(b)$ the number of small $(<3.5 \mathrm{~mm}$ in diameter; solid bar) and large $(\geqslant 3.5 \mathrm{~mm}$ in diameter; hatched bar) ovarian follicles detected by daily ultrasound per ewe (data from Groups 1 and 2 pooled). The summation of small and large indicate the total number of follicles. Values are means \pm S.E.M. ${ }^{*} P<0.05$ or ${ }^{* *} P<0.01$ indicates significance of the difference from preceding time point for follicle diameter and number of small and large follicles, while $+P<0.05$ or $++P<0 \cdot 01$ indicates significance of difference from preceding time point for total number of follicles (repeated samples ANOVA).

\section{Acknowledgements}

We gratefully acknowledge the technical assistance of Miss B W Gordon and the help of Dr J A Downing in preparing the ovarian autotransplants. We thank Dr H M Picton for helpful discussions during the preparation of this manuscript. We thank the National Institute of Health and National Institute of Arthritis, Diabetes and Digestive and Kidney Diseases for provision of gonadotrophin preparations and the Salk Institute, San Diego, California for donation of the GnRH antagonist. This work was supported by an Australian Wool Corporation grant (CPB51) and B K C was supported by a National Research Fellowship from the Australian Research Council.

\section{References}

Adams GP, Matteri RL, Kastelic JP, Ko JCH \& Ginther OJ 1992 Association between surges of follicle-stimulating hormone and the emergence of follicular waves in heifers. Journal of Reproduction and Fertility 94 177-188.

Armstrong DT, Siuda A, Opavsky MA \& Chandrasekhar Y 1989 Bimodal effects of luteinizing hormone and role of androgens in modifying superovulatory responses of rats to infusion with purified porcine follicle-stimulating hormone. Biology of Reproduction $\mathbf{4 0}$ $54-62$.

Baird DT 1983 Factors regulating the growth of the preovulatory follicle in the sheep and human. Journal of Reproduction and Fertility $69343-352$.

Baird DT \& McNeilly AS 1981 Gonadotrophic control of follicular development and function during the oestrous cycle of the ewe. Journal of Reproduction and Fertility 30 (Suppl) 119-133.

Baird DT \& Scaramuzzi RJ 1976 Changes in the secretion of ovarian steroids and pituitary luteinizing hormone in the peri-ovulatory period in the ewe: the effect of progesterone. Journal of Endocrinology $70237-245$.

Baird DT, Swanston I \& Scaramuzzi RJ 1976 Pulsatile release of LH and secretion of ovarian steroids in sheep during the luteal phase of the estrous cycle. Endocrinology 98 1490-1496.

Baird DT, Campbell BK \& McNeilly AS 1990 Ovine follicular fluid suppresses the ovarian secretion of androgens, oestradiol and inhibin. Journal of Endocrinology 127 23-32.

Baird DT, Campbell BK, Mann GE \& McNeilly AS 1991 Inhibin and oestradiol in the control of FSH secretion in the sheep. Journal of Reproduction and Fertility 43 (Suppl) 125-138.

Campbell BK \& Scaramuzzi RJ 1995 The effect of acute immuno-neutralisation of inhibin in ewes during the late luteal phase of the oestrous cycle on ovarian hormone secretion and follicular development during the subsequent follicular phase. Journal of Reproduction and Fertility 104 337-345.

Campbell BK, McNeilly AS, Picton HM \& Baird DT 1990 The effect of a potent Gn-RH antagonist on ovarian secretion of oestradiol inhibin and androstenedione and the concentration of $\mathrm{LH}$ and FSH during the follicular phase of the sheep oestrous cycle. Journal of Endocrinology 126 377-384.

Campbell BK, Picton HM, Mann GM, McNeilly AS \& Baird DT 1991 The effect of steroid- and inhibin-free ovine follicular fluid on ovarian follicle populations and ovarian hormone secretion. Journal of Reproduction and Fertility 93 81-96.

Campbell BK, Dobson H, Friend M, Gordon BM \& Scaramuzzi RJ 1992 Dose-time relationships of a potent GnRH antagonist on gonadotrophin secretion in ewes. Symposium on Gonadotrophins, GnRH, GnRH Analogs and Gonadal Peptides, pp 77. Eds P Bouchard, A Caraty \& S Pavlou. Paris, August 1992. London: Parthenon.

Campbell BK, Gordon BM, Dobson H \& Scaramuzzi RJ 1993 The relative role of LH and FSH in the growth and development of pre-ovulatory follicles. Journal of Reproduction and Fertility Abstract Series II 2116.

Campbell BK, Gordon BM \& Scaramuzzi RJ 1994 The effect of ovarian arterial infusion of transforming growth factor $\alpha$ on ovarian hormone secretion by ewe with an autotransplanted ovary. Journal of Endocrinology 143 13-24.

Campbell BK, Gordon BM, Tsonis CG \& Scaramuzzi RJ 1995 The effect of acute immuno-neutralisation of inhibin in ewes during the early luteal phase of the oestrous cycle on ovarian hormone secretion and follicular development. Journal of Endocrinology 145 479-490. 
Campbell BK, Baird DT \& Webb R 1996 Ovine theca cells are differentially responsive to $\mathrm{LH}$ in serum-free culture. Journal of Reproduction and Fertility Abstract Series 1795.

Chupin D, Cognie Y, Combarnous Y, Procureur R \& Saumande J 1987 Effect of purified LH and FSH on ovulation in the cow and ewe. In Follicle Growth and Ovulation Rate in Farm Animals, pp 63-72. Eds JF Roche \& D O’Callaghan. Dordrecht: Martinus Nijhoff.

Collett RA, Land RB \& Baird DT 1973 The pattern of progesterone secretion by the autotransplanted ovary of the ewe in response to ovine luteinizing hormone. Journal of Endocrinology 56 403-411.

Devroey P, Mannaerts B, Smitz J, Bennink HC \& Vansteirteghem M 1994 Clinical outcome of a pilot efficacy study on recombinant human follicle-stimulating-hormone (ORG-32489) combined with various gonadotropin-releasing-hormone agonist regimens. Human Reproduction 9 1064-1069.

Evans G, Brooks J, Struthers W \& McNeilly AS 1994 Superovulation and embryo recovery in ewes treated with gonadotrophin-releasing hormone agonist and purified follicle-stimulating hormone. Reproduction, Fertility and Development 6 247-252.

Fabrenys C, Martin GB \& Venier G 1993 Analysis of the hormonal control of female sexual behavior and the preovulatory LH surge in the ewe - roles of quantity of estradiol and duration of its presence. Hormones and Behavior 27 108-121.

Ginther OJ, Kot K \& Wiltbank MC 1995 Association between emergence of follicular waves and fluctuations in FSH concentrations during the estrous cycle in ewes. Theriogenology $\mathbf{4 2}$ 689-703.

Goding JR, McCracken JA \& Baird DT 1967 The study of ovarian function in the ewe by means of a vascular autotransplantation technique. Journal of Endocrinology 39 37-52.

Gong JG, Campbell BK, Bramley TA, Gutierrez CG, Peters AR \& Webb R 1996a Suppression in the secretion of follicle-stimulating hormone and luteinizing hormone, and ovarian follicle development in heifers continuously infused with gonadotrophin-releasing hormone agonist. Biology of Reproduction 55 68-74.

Gong JG, Campbell BK \& Webb R $1996 b$ Effects of infusion with $\mathrm{FSH}$, with or without $\mathrm{LH}$, on ovarian follicle growth and development in GnRH agonist-treated heifers. Journal of Reproduction and Fertility Abstract Series 185.

Harper MJK 1988 Gamete and zygote transport. In Physiology of Reproduction, pp 103-134. Eds E Knobil \& J Neill. New York: Raven Press Ltd.

Hillier SG 1987 Sex steroid metabolism and follicular development in the ovary. Oxford Reviews of Reproductive Biology 7 168-222.

Howles CM, Loumaye L, Giroud D \& Luyet G 1994 Multiple follicular development and ovarian steroidogenesis following subcutaneous administration of a highly purified urinary FSH preparation in pituitary desensitized women undergoing IVF - a multicenter European phase-III study. Human Reproduction 9 424-430.

Karnitis VJ, Townson DH, Friedman CI \& Danforth DR 1994 Recombinant human follicle-stimulating hormone stimulates multiple follicular growth, but minimal estrogen production in gonadotropin-releasing hormone antagonist-treated monkeys: examining the role of luteinizing hormone in follicular development and steroidogenesis. Journal of Clinical Endocrinology and Metabolism 79 91-97.

Karsch FJ, Bittman EL, Foster DL, Goodman RL, Legan SJ \& Robinson JE 1984 Neuroendocrine basis of seasonal reproduction. Recent Progress in Hormone Research 40 185-225.

Lamming GE \& Mann GE 1995 Control of endometrial oxytocin receptors and prostaglandin-F2-alpha production in cows by progesterone and oestradiol. Journal of Reproduction and Fertility 103 69-73.

McNatty KP, Gibb M, Dobson C \& Thurley DC 1981 Evidence that changes in luteinizing hormone secretion regulate the growth of the preovulatory follicle in the ewe. Journal of Endocrinology 90 375-389.

McNeilly AS, Swanston IA, Crow W, Tsonis CG \& Baird DT 1989 Changes in the plasma concentrations of inhibin throughout the normal sheep oestrous cycle and after the infusion of FSH. Journal of Endocrinology 120 295-305.

McNeilly AS, Picton HM, Campbell BK \& Baird DT 1991 Gonadotrophic control of follicle growth in the ewe. Journal of Reproduction and Fertility 43 (Suppl) 177-186.

Moor RM, Polge C \& Willadsen SM 1980 Effects of follicular steroids on the maturation and fertilization of mammalian oocytes. Journal of Embryology and Experimental Morphology 56 319-335.

Murphy BD, Mapletoft RJ, Manns J \& Humphrey WD 1984 Variability in gonadotropin preparations as a factor in the superovulatory response. Theriogenology 21 117-125.

Picton HM \& McNeilly AS 1991 Effect of basal and pulsatile LH release on FSH-stimulated follicle growth in ewes chronically treated with gonadotrophin-releasing hormone agonist. Journal of Endocrinology 128 449-456.

Picton HM, Tsonis CG \& McNeilly AS 1990a FSH causes a time-dependent stimulation of preovulatory follicle growth in the absence of pulsatile LH secretion in ewes chronically treated with gonadotrophin-releasing hormone agonist. Journal of Endocrinology 126 297-307.

Picton HM, Tsonis CG \& McNeilly AS $1990 b$ The antagonistic effect of exogenous LH pulses on FSH-stimulated preovulatory follicle growth in ewes chronically treated with a gonadotrophin-releasing hormone agonist. Journal of Endocrinology 127 273-283.

Radford HM, Watson RH \& Wood GF 1960 A crayon and associated harness for the detection of mating under field conditions. Australian Veterinary Journal 36 57-66.

Savio JD, Thatcher WW, Badinga L, de la Sota RL \& Wolfenson D 1993 Regulation of dominant follicle turnover during the oestrous cycle in cows. Journal of Reproduction and Fertility 97 197-203.

Scaramuzzi RJ, Adams NR, Baird DT, Campbell BK, Downing JA, Findlay JK, Henderson KM, Martin GB, McNatty KP, McNeilly AS \& Tsonis CG 1993 A model for follicle selection and the determination of ovulation rate in the ewe. Reproduction, Fertility and Development 5 459-478.

Sirois J \& Fortune JE 1988 Ovarian follicular dynamics during the estrus cycle in heifers monitored by real time ultrasound. Biology of Reproduction 39 308-317.

Souza CJH, Campbell BK \& Baird DT 1996 Follicular dynamics and ovarian steroid secretion in sheep during anoestrus. Journal of Reproduction and Fertility 108 101-106.

Souza CJH, Campbell BK \& Baird DT 1997a Follicular waves and ovarian hormone secretion in sheep during the luteal phase of the oestrous cycle. Journal of Endocrinology (In Press).

Souza CJH, Campbell BK \& Baird DT 1997b Follicular dynamics and ovarian steroid secretion in sheep during the follicular and early luteal phases of the estrous cycle. Biology of Reproduction $\mathbf{5 6}$ 483-488.

Wallace JM \& McNeilly AS 1986 Changes in FSH and the pulsatile secretion of LH during treatment of ewes with bovine follicular fluid throughout the luteal phase of the oestrous cycle. Journal of Endocrinology 111 317-327.

Webb R \& Gauld IK 1987 Endocrine control of follicular growth in the ewe. In Follicular Growth and Ovulation Rate in Farm Animals, pp 107-118. Eds JF Roche \& D O'Callaghan. Dordrecht: Martinus Nijhoff.

Webb R, Gong JG, Law AS \& Rusbridge SM 1992 Control of ovarian function in cattle. Journal of Reproduction and Fertility 45 (Suppl) 141-156.

Whisnant CS, Havern RL \& Goodman RL 1991 Endogenous opioid suppression of luteinizing-hormone pulse frequency and amplitude in the ewe - hypothalamic sites of action. Neuroendocrinology 54 $587-593$. 
Wright RW, Bondioli K, Grammer J, Kuzan F \& Menino DJ 1981 FSH or FSH plus LH superovulation in ewes following estrus synchronization with medroxyprogesterone acetate pessaries. Journal of Animal Science $\mathbf{5 2}$ 115-118.

Yeoman RR, Williams LE, Aksel S, Helvacioglu A, Bowers CY, Kuehl TJ \& Abee CR 1995 Comparison of GnRH agonist and antagonist pituitary suppression during superovulation in the squirrel-monkey. Biology of Reproduction 52 Abstract 66.
Zelinski-Wooten MB, Hutchison JS, Hess DL, Wolf DP \& Stouffer RL 1995 Follicle stimulating hormone alone supports follicle growth and oocyte development in gonadotrophin-releasing hormone antagonist treated monkeys. Human Reproduction 10 1658-1666.

Received 22 April 1996

Revised manuscript received 28 February 1997

Accepted 15 April 1997 